\title{
Conflict and Disease: A Complex Relationship
}

\section{Robert A. FRANK* 1}

1 Student, University of Ottawa, Canada

*Auteur(e) correspondant | Corresponding author : rfrano48@uottawa.ca

Societies will always be subjected to situations that test their tolerance thresholds. When a stressor exceeds a society's capacity to cope, "failure" of the system is often manifested as social unrest, falling along a spectrum of intensity ranging from civil wars and revolutions to riots, strikes, and protests (Braha, 2012). The conflict leading to social unrest is most often initiated by groups on the disadvantaged end of systemic inequalities, as a desperate effort at effecting change (Haas, 1986). Although social unrest is sometimes a necessary vehicle for cultural revolution, the resultant disruption of society invariably creates a volatile environment that is vulnerable to adverse health outcomes (Jovanović, Renn, \& Schröter, 2012).

Societal health is an area that is particularly susceptible to disruption as a result of social unrest. In addition, some factors contributing to social unrest are independent determinants of health that directly promote adverse health consequences. Social unrest is a powerful warning sign for negative health outcomes due to its direct disruptive effects in addition to the simultaneous and independent influences of racial tensions, socioeconomic inequality, and economic collapse on both civil stability and societal health. Thus, healthcare providers must exercise a heightened level of vigilance in communities experiencing conflict.

\section{Health consequences of social unrest}

Disorder in society predisposes citizens to an inherently elevated risk of poor health outcomes. Aside from the burden placed on the medical system by physical injuries resulting from violent conflict (Ballantyne, 2006), various underlying consequences of social unrest indirectly impair health. Firstly, the displacement of individuals from their home regions as a result of local conflict is often associated with an increased incidence of infectious disease. Due to differences in endemic organisms between regions, displaced individuals can introduce new infectious agents into their places of refuge, while being susceptible to infection by the endemic organisms of their new locations (World Health Organization, 2000). The increased likelihood of injury and illness in turbulent situations is compounded by inhibited access to, and utilization of, health services. Amidst turmoil, physicians may feel pressured to relocate for political or safety reasons, leaving fewer healthcare pro- viders for the remaining citizens. Depending on the extent of conflict, physical barriers, such as transportation blockades, may explicitly prevent individuals from accessing any available healthcare that remains. Even in the absence of such barriers, fear for personal safety may result in a negative correlation between healthcare seeking and the amount of conflict-related violence (Price \& Bohara, 2012). In extreme cases, violent unrest can result in destruction of health posts, as well as kidnapping and torture of healthcare providers (Devkota \& Teijlingen, 2010; Collins, 2006). Consequently, safety considerations may deter health aid organizations from serving these volatile regions (CLAS Berkeley, 2015). Social unrest produces various conditions that exert a direct impact on the health of those involved.

\section{Impact of Ethnic Inequality}

Cultural and ethnic inequalities create societal tensions that contribute to interpersonal conflict. When a division of power exists between ethnic groups, the relatively deprived group will inevitably perceive unfavourable biases in multiple settings. Furthermore, inequalities that arise from identity-based divisions tend to amplify negative perceptions, while simultaneously enhancing solidarity among the disadvantaged group, thereby inciting conflict and rebellion

(Ostby, 2008). Even when conflict has not erupted, the pervasive tensions that exist between races can interfere with the provision of adequate healthcare. Many African American patients distrust their Caucasian physicians due in part to expectations of racism and financial discrimination. A lack of trust reduces the likelihood of healthcare-seeking and hinders patient compliance (Jacobs, 2006). However, a patient's distrust is not always unwarranted. Physicians may perpetuate perceptions of racism via alterations in their approaches to medical care based on patients' ethnicities (Wellesley Institute, 2012). Given the importance of the doctor-patient relationship in producing favourable outcomes, compromised rapport due to racial conflict presents a major barrier to healthcare.

\section{Impact of Socioeconomic Disadvantage}

The limited resource accessibility experienced by communities at socioeconomic disadvantage creates a culture of hostility towards societal institutions. The isolation experi- 
enced in impoverished regions can result in distrust of mainstream society and aggression toward established institutions, contributing to social unrest (Polisen, n.d.). Medical care is among the most important resources to which individuals in disadvantaged areas have limited access. Affected individuals are less likely to have regular healthcare providers or to obtain preventative services, regardless of the availability of these resources (Kirby \& Kaneda, 2005), possibly due to limited education and negative perceptions of mainstream society. Ironically, these individuals are often in the greatest need of healthcare services, given the adverse health behaviours such as poor diets, smoking, obesity, and inactivity associated with lower socioeconomic status (Darmon \& Drewnowski, 2008; Pampel, Krueger, \& Denney, 2010). Thus, disadvantaged communities are not only in a position of social volatility, but are simultaneously burdened with reduced baseline health status and subsequent barriers to improvement.

\section{Impact of Economic Instability}

Financial crises hinder quality of life, while promoting redistribution of funds away from areas that are most beneficial to citizens. A common feature of economic crises is a rapid increase in unemployment, which often results in instability and mass protest (International Labour Organization, 2013). The uncertainty associated with financial loss is also a significant stressor that can negatively impact mental and physical health. Throughout the economic crisis in Greece, mental illness and suicide rates have increased significantly, while HIV rates have also increased due to intravenous drug utilization (Simou \& Koutsogeorgou, 2014). Furthermore, many individuals are thrust into poverty and subsequently face the barriers associated with low socioeconomic status. Despite the significant impact of economic collapse on societal health, the quality of healthcare is often paradoxically sacrificed due to reallocation of limited funds, as highlighted by the funding cuts to mental health and drug abuse prevention programs in Greece during its economic struggles (Simou \& Koutsogeorgou, 2014). A society in economic crisis, therefore, faces a conflicting scenario with increased demand for, but reduced supply of, health services.

\section{Role of Healthcare Professionals}

The profound health-related impact of social unrest reflects a need for healthcare professionals to take action. The approach to alleviating the negative health consequences of social unrest includes eliminating the cause, and mitigating the damage. The powerful collective voice of physicians advocating for change can be utilized to modify factors that are strongly rooted in society. Promoting racial equality, encouraging fair distribution of resources towards the support of individuals in disadvantaged communities, and encouraging prioritization of healthcare in government fund allocation, could all reduce social unrest and its associated health consequences. However, given that systemic change cannot occur instantaneously, social unrest is inevitable and physicians must aim to minimize health consequences when conflict arises. The first and most important step is recognition of social unrest and identification of the responsible determinants. Healthcare providers should exercise heightened vigilance in communities experiencing conflict, to facilitate recognition of affected patients and initiation of preventative interventions. Social unrest in a given community should be noted as a risk factor for affected patients, prompting arrangement of interdisciplinary community resources, such as housing, vocational, and educational supports. Astute physicians should also demonstrate neutrality and professionalism in these situations, ensuring that all patients feel comfortable in the healthcare environment and that the physician-patient relationship does not suffer during times of hostility. Finally, physicians practicing in areas of persistent conflict can consider decentralizing or mobilizing their services in order to provide patients with safer means of accessing care.

While countless factors can contribute to social unrest, those with independent effects on both the stability and health of societies are of particular concern due to compounded health consequences. Given that social unrest stems from inequalities, worsening health outcomes in the disadvantaged group may contribute to further disparity, which could subsequently enhance social unrest, creating a vicious cycle of societal conflict and adverse health outcomes (Figure 1). Although physicians are traditionally most comfortable treating existing disease, primary prevention is the most effective means of eliminating adverse health outcomes. Physicians must break the cycle of unrest and disease in order to promote health stability in an inevitably unstable world.

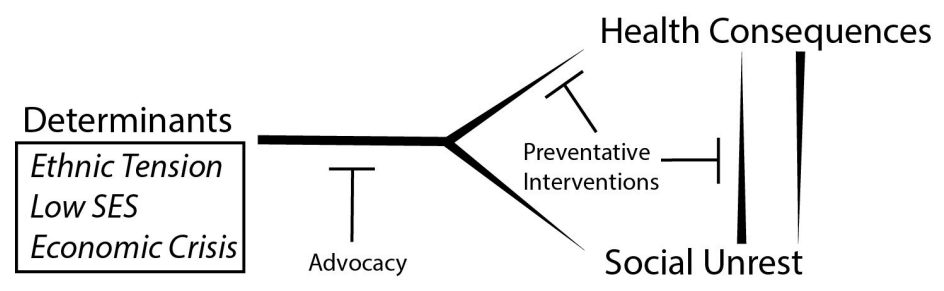

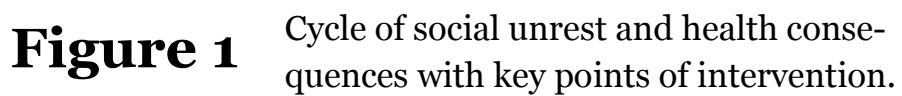




\section{References}

Ballantyne, B. (2006). Medical management of the traumatic consequences of civil unrest incidents. Toxicological Reviews, 25(3), 155-197. http://

dx.doi.org/10.2165/00139709-200625030-00003

Braha, D. (2012). Global civil unrest: Contagion, selforganization, and prediction. PLOS ONE, 7(10). http:// dx.doi.org/10.1371/journal.pone.0048596

Collins, S. (2006). Assessing the health implications of Nepal's ceasefire. The Lancet, 368(9539), 907-908. http:// dx.doi.org/10.1016/So140-6736(06)69353-7

CLAS Berkeley. (2015, August 13). Health and justice in high-conflict areas. Retrieved from http://

clas.berkeley.edu/research/healthcare-health-and-justicehigh-conflict-areas

Darmon, N., \& Drewnowski, A. (2008). Does social class predict diet quality? The American Journal of Clinical Nutrition, 87(5), 1107-1117. http://dx.doi.org/ 10.1093/nutrit/ nuvo27

Devkota, B., \& van Teijlingen, E. R. (2010). Understanding effects of armed conflict on health outcomes: The case of Nepal. Conflict and Health, 4(1), 20. http://

dx.doi.org/10.1186/1752-1505-4-20

Haas, Michael. (1986). Metaphysics of paradigms in political science: Theories of urban unrest. The Review of Politics, 48(4), 520-548. http://dx.doi.org/10.1017/

So034670500039668

International Labour Organization. (2013, July 8). Are economic stagnation and unemployment fueling social unrest? Retrieved from http://www.ilo.org/newyork/voicesat-work/WCMS_217280/lang-en/index.htm

Jacobs, E. A. (2006). Understanding African Americans' views of the trustworthiness of physicians. Journal of General Internal Medicine, 21(6), 642-647. http://

dx.doi.org/10.1111/j.1525-1497.2006.00485.x

Jovanović, A. S., Renn, O., \& Schröter, R. (2012). Social unrest. Paris: OECD Publishing. http:// dx.doi.org/10.1787/9789264173460-1-en

Kirby, J. B., \& Kaneda, T. (2005). Neighborhood socioeconomic disadvantage and access to health care. Journal of Health and Social Behavior, 46(1), 15-31. http:// dx.doi.org/ 10.1177/002214650504600103

Østby, G. (2008). Polarization, horizontal inequalities and violent civil conflict. Journal of Peace Research, 45(2), 143 -162. http://dx.doi.org/10.1177/0022343307087169

Pampel, F. C., Krueger, P. M., \& Denney, J. T. (2010). Socioeconomic disparities in health behaviors. Annual Review of Sociology, 36(1), 349-37o. http://dx.doi.org/10.1146/ annurev.soc.012809.102529

Polisen (n.d.). Earlier research. Retrieved from https:// polisen.azurewebsites.net/index.php/social-unrest/earlierresearch/

Price, J. I., \& Bohara, A. K. (2012). Maternal health care amid political unrest: The effect of armed conflict on antenatal care utilization in Nepal. Health Policy and Planning, 28(3), 309-319. http://dx.doi.org/ 10.1093/heapol/ czso62

Simou, E., \& Koutsogeorgou, E. (2014). Effects of the economic crisis on health and healthcare in Greece in the literature from 2009 to 2013: A systematic review. Health Policy, 115(2-3), 111-119. http://dx.doi.org/10.1016/

j.healthpol.2014.02.002

Wellesley Institute. (2012, February 1). Colour coded health care: The impact of race and racism on Canadians' health. Retrieved from http://www.wellesleyinstitute.com/ health/colour-coded-health-care-the-impact-of-race-andracism-on-canadians-health/

World Health Organization. (2000). WHO report on global surveillance of epidemic-prone infectious diseases. Retrieved from http://www.who.int/iris/ handle/10665/66485 